\title{
Chemical polymorphism and antifungal activity of essential oils from leaves of different provenances of indigenous cinnamon (Cinnamomum osmophloeum)
}

\author{
Sen-Sung Cheng ${ }^{\text {a }}$, Ju-Yun Liu ${ }^{\text {a }}$, Yen-Ray Hsui ${ }^{b}$, Shang-Tzen Chang ${ }^{\text {a,* }}$ \\ ${ }^{a}$ School of Forestry and Resource Conservation, National Taiwan University, No. 1, Section 4, Roosevelt Road, Taipei 106, Taiwan \\ ${ }^{\mathrm{b}}$ Division of Silviculture, Taiwan Forestry Research Institute, No. 53, Nan-Hai Road, Taipei 100, Taiwan
}

Received 20 September 2004; received in revised form 5 February 2005; accepted 10 February 2005

Available online 13 April 2005

\begin{abstract}
The essential oils isolated from nine geographical provenances of indigenous cinnamon (Cinnamomum osmophloeum Kaneh.) leaves were examined by GC-MS and their chemical constituents were compared. According to GC-MS and cluster analyses the leaf essential oils of the nine provenances and their relative contents were classified into six chemotypes - cinnamaldehyde type, cinnamaldehyde/cinnamyl acetate type, cinnamyl acetate type, linalool type, camphor type and mixed type. In addition, the antifungal activities of leaf essential oils and their constituents from six chemotypes of indigenous cinnamon were investigated in this study. Results from the antifungal tests demonstrated that the leaf essential oils of cinnamaldehyde type and cinnamaldehyde/cinnamyl acetate type had an excellent inhibitory effect against white-rot fungi, Trametes versicolor and Lenzites betulina and brown-rot fungus Laetiporus sulphureus. The antifungal indices of leaf essential oils from these two chemotypes at the level of $200 \mu \mathrm{g} / \mathrm{ml}$ against $T$. versicolor, L. betulina and $L$. sulphureus were all $100 \%$. Among them, the $\mathrm{IC}_{50}(50 \%$ of inhibitory concentrations) value of the essential oil of cinnamaldehyde type leaf against $L$. sulphureus was $52-59 \mu \mathrm{g} / \mathrm{ml}$. Cinnamaldehyde possessed the strongest antifungal activities in comparison with other constituents of the essential oils from cinnamaldehyde type leaf, at the level of $100 \mu \mathrm{g} / \mathrm{ml}$ its antifungal indices against $T$. versicolor, L. betulina and $L$. sulphureus were $100 \%$. The $\mathrm{IC}_{50}$ values of cinnamaldehyde against $T$. versicolor, $L$. betulina and L. sulphureus were 73,74 and $73 \mu \mathrm{g} / \mathrm{ml}$, respectively.
\end{abstract}

(c) 2005 Elsevier Ltd. All rights reserved.

Keywords: Cinnamomum osmophloeum; Essential oils; Leaf; Chemotypes; GC-MS; Cinnamaldehyde; Antifungal activity

\section{Introduction}

Lauraceae is an economically important family consisting mostly of trees. The genus Cinnamomum comprises about 250 species that are distributed in Asia and Australia (Jayaprakasha et al., 2003). Indigenous cinnamon (Cinnamomum osmophloeum kaneh.) (Cinnamomum) is an endemic tree that grows in Taiwan's natural hardwood forests at elevations between 400 and

\footnotetext{
* Corresponding author. Tel.: +88623366 4626; fax: +88622365 4520.

E-mail address: peter@ntu.edu.tw (S.-T. Chang).
}

$1500 \mathrm{~m}$ (Liu et al., 1998). Hu et al. (1985) analyzed composition of essential oils of C. osmophloeum leaves collected randomly from 21 provenances in central, southern, and eastern parts of Taiwan and found that cinnamaldehyde was the major constituent of some C. osmophloeum provenances and that eugenol was present in other C. osmophloeum provenances. Based on differences in chemical composition of leaf essential oil, C. osmophloeum was classified into nine types: cassia type, cinnamaldehyde type, coumarin type, linalool type, eugenol type, camphor type, 4-terpinenol type, linalool/terpinenol type, and mixed type $(\mathrm{Hu}$ et al., 1985). 
C. osmophloeum has been of interest to researchers because the chemical constituents of its leaf essential oil are similar to those of Cinnamomum cassia bark oil (Chang et al., 2001; Hu et al., 1985). Cinnamon oil is commonly used in the food industry because of its special aroma. In addition, its antimicrobial and antifungal properties have also drawn great attention from many researchers (Chang et al., 2001; Hili et al., 1997; Kim et al., 2004; Ouattara et al., 1997; Park et al., 2000; Singh et al., 1995). Our previous studies have demonstrated that leaf essential oils from cinnamaldehyde type of C. osmophloeum had excellent antitermite, antibacterial, antimite, antimildew, antimosquito and antipathogenic activities (Chang et al., 2001; Chang and Cheng, 2002; Chen et al., 2002; Chen and Chang, 2002; Cheng et al., 2004a; Lee et al., 2005). However, to the best of our knowledge there is no literature concerning the antifungal activities of leaf essential oils and their constituents from different provenances of C. osmophloeum against wood decay fungi. In light of the possible existence of chemical polymorphism of leaf essential oils from different provenances of $C$. osmophloeum, it is interesting to study differences in the bioactivity of varieties of indigenous cinnamon leaf oils. In this study leaf essential oils from nine C. osmophloeum provenances (Table 1, CO1-CO9) were analyzed by GC-MS for their chemical composition and the antifungal activities of these leaf essential oils were also investigated.

\section{Methods}

\subsection{Plant material}

Leaves of nine $C$. osmophloeum provenances (CO1CO9) were collected in September 2002 from the Lien Hua-Chin Research Center and the Da-Pin-Ting of Taiwan Sugar Farm located in Nantou County in central Taiwan. The species were identified by Mr. Yen-Ray Hsui of the Taiwan Forestry Research Institute, and voucher specimens were deposited at the laboratory of wood chemistry (School of Forestry and Resource Conservation, National Taiwan University).

\subsection{Distillation of essential oils}

Fresh $C$. osmophloeum leaves were cleaned with distilled water and air-dried to MC $40 \%$ at room temperature $\left(27^{\circ} \mathrm{C}\right)$, the air-dried samples $(150 \mathrm{~g}$ each), in triplicate, were subjected to hydrodistillation in a Clevenger-type apparatus for $6 \mathrm{~h}$ (Chang et al., 2001), followed by determination of oil contents. Leaf essential oils were stored in airtight containers prior to analysis by gas chromatography-mass spectrometry (GC-MS).

\section{3. $G C-M S$ analysis}

Leaf essential oils were analyzed by a Trace GCPoLaris Q mass (ion source $200{ }^{\circ} \mathrm{C}, 70 \mathrm{eV}$ ) instrument, equipped with an RTx-5MS capillary column $(30 \mathrm{~m} \times 0.25 \mathrm{~mm}$, film thickness $0.25 \mu \mathrm{m})$. The oven temperature was held at $80^{\circ} \mathrm{C}$ for $1 \mathrm{~min}$, then programmed to increase from 80 to $200{ }^{\circ} \mathrm{C}$ at a rate of $4^{\circ} \mathrm{C} / \mathrm{min}$ and held for $5 \mathrm{~min}$. Injector temperature, $250{ }^{\circ} \mathrm{C}$; split ratio, 1:10; carrier gas, helium at a flow rate of $1 \mathrm{ml} / \mathrm{min}$; injection volume, $1 \mathrm{ml}$. Identification of the major components of $C$. osmophloeum leaf oils was confirmed by comparison with standards, by spiking, and on the basis of their mass spectral fragmentation using the Wiley/NBS Registry of Mass Spectral library and NIST MS Search. The quantity of compounds was obtained by integrating the peak area of the spectrograms.

\subsection{Antifungal assays}

Two white-rot fungi, Lenzites betulina (CCRC 35296) and Trametes versicolor (CCRC 35253) and one brownrot fungus, Laetiporus sulphureus (CCRC 35305), were used in this experiment. The method of Chang et al. (1999) was employed for antifungal evaluation of both the essential oil and its main constituents. Briefly, 500, 200,100 and $50 \mu \mathrm{g} / \mathrm{ml}$ of essential oils were added to sterilized potato dextrose agar (PDA) in $9 \mathrm{~cm}$ Petri dish. After transferring the mycelium of three fungi strains, the testing dishes were incubated at $26 \pm 2{ }^{\circ} \mathrm{C}, 70 \%$ relative humidity. When the mycelium of fungi reached the edges of control dishes (without adding essential oils or constituents) for $\approx 10-14 \mathrm{~d}$, the antifungal indices were calculated. Each test was repeated three times, and the data averaged. The $\mathrm{IC}_{50}$ values (the concentration in $\mu \mathrm{g} / \mathrm{ml}$ that inhibited $50 \%$ of the mycelium of fungi growth) were calculated by probit analysis. Didecyl dimethyl ammonium chloride (DDAC), a commercially available fungicide, was used as a reference compound. The formula of antifungal indices was shown as follows:

Antifungal index $(\%)=\left(1-\frac{\mathrm{Da}}{\mathrm{Db}}\right) \times 100$,

$\mathrm{Da}$, the diameter of growth zone in the experimental dish $(\mathrm{cm}) ; \mathrm{Db}$, the diameter of growth zone in the control dish $(\mathrm{cm})$.

\subsection{Cluster analysis}

The cluster analysis was performed with multi-variate statistical package (MVSP) software to identify relatively homogeneous groups of nine provenances (CO1$\mathrm{CO} 9$ ) of $C$. osmophloeum based on percent composition of their essential oil samples. Euclidean distance was selected as a measure of similarity, and the unweighted 
Table 1

Chemical compositions of leaf essential oils from nine provenances of C. osmophloeum

\begin{tabular}{|c|c|c|c|c|c|c|c|c|c|c|}
\hline Compounds & $\mathrm{RT}^{\mathrm{a}}$ & $\mathrm{CO} 1$ & $\mathrm{CO} 2$ & $\mathrm{CO} 3$ & $\mathrm{CO} 4$ & $\mathrm{CO} 5$ & $\mathrm{CO} 6$ & $\mathrm{CO} 7$ & $\mathrm{CO} 8$ & $\mathrm{CO} 9$ \\
\hline Monoterpene hydrocarbons (\%) & & 0.0 & 0.0 & 9.0 & 0.0 & 12.3 & 0.0 & 0.0 & 0.0 & 0.0 \\
\hline Camphene & 4.33 & $-{ }^{\mathrm{b}}$ & - & 9.0 & - & 0.6 & - & - & - & - \\
\hline$\beta$-Pinene & 4.65 & - & - & - & - & 2.2 & - & - & - & - \\
\hline$p$-Cymene & 5.38 & - & - & - & - & - & - & - & - & - \\
\hline Limonene & 5.45 & - & - & - & - & 8.7 & - & - & - & - \\
\hline$\alpha$-Terpinene & 6.74 & - & - & - & - & 0.8 & - & - & - & - \\
\hline Oxygenated monoterpenes (\%) & & 4.7 & 1.6 & 1.4 & 12.0 & 73.4 & 87.5 & 0.7 & 1.0 & 5.4 \\
\hline Linalool oxide & 6.77 & - & - & - & - & - & 0.5 & - & - & - \\
\hline Linalool & 6.93 & - & - & - & 0.5 & - & 86.6 & - & - & - \\
\hline Camphor & 8.29 & - & - & 0.8 & - & 43.8 & - & - & - & - \\
\hline Borneol & 8.80 & - & - & - & 0.3 & 0.9 & - & - & - & - \\
\hline Terpinene-4-ol & 9.11 & - & - & - & - & 4.3 & - & - & - & - \\
\hline$\alpha$-Terpineol & 9.42 & - & - & 0.2 & 0.8 & 2.0 & 0.4 & - & - & - \\
\hline Geraniol & 11.13 & - & - & - & 0.6 & 1.7 & - & - & - & - \\
\hline Citral & 11.78 & - & - & - & - & - & - & - & - & - \\
\hline Bornyl acetate & 12.15 & 4.7 & 1.6 & 0.4 & 9.8 & 20.6 & - & 0.7 & 1.0 & 1.0 \\
\hline Geranyl acetate & 14.44 & - & - & - & - & - & - & - & - & 4.4 \\
\hline Sesquiterpene hydrocarbons (\%) & & 7.9 & 2.6 & 1.9 & 19.7 & 4.6 & 2.5 & 1.1 & 1.7 & 7.2 \\
\hline Cyclosativene & 14.57 & - & - & - & 0.4 & - & - & - & - & - \\
\hline$\alpha$-Cubebene & 14.84 & 0.6 & - & - & 3.0 & - & - & - & - & - \\
\hline$\alpha$-Fenchene & 14.94 & - & - & - & - & 1.5 & - & - & - & - \\
\hline Humulen & 15.30 & - & - & - & 0.2 & - & - & - & - & - \\
\hline$\beta$-Caryophyllene & 16.19 & 4.7 & 1.1 & 1.0 & - & 1.6 & 1.3 & 0.8 & 1.3 & - \\
\hline$\alpha$-Caryophyllene & 17.23 & 0.8 & - & - & - & - & - & - & - & - \\
\hline Aromadendrene & 17.42 & - & - & - & 3.0 & - & - & - & - & - \\
\hline T-Muurolene & 17.82 & - & - & - & 1.8 & - & - & - & - & - \\
\hline Valencene & 17.95 & - & - & - & 0.5 & - & - & - & - & - \\
\hline$\alpha$-Muurolene & 18.51 & - & - & - & 1.2 & - & - & - & - & 0.4 \\
\hline$\delta$-Cadinene & 18.65 & - & - & - & - & - & 0.7 & 0.3 & 0.4 & 2.1 \\
\hline$\gamma$-Muurolene & 18.94 & - & - & - & 1.8 & - & - & - & - & - \\
\hline$\beta$-Cadinene & 19.19 & 0.6 & 0.6 & 0.7 & 1.4 & 0.6 & - & - & - & 3.0 \\
\hline$\gamma$-Elemene & 20.23 & 0.7 & 0.5 & 0.2 & 0.5 & 0.9 & - & - & - & 0.5 \\
\hline Isoledene & 20.80 & 0.5 & - & - & 2.2 & - & 0.5 & - & - & 1.2 \\
\hline$\alpha$-Guaiene & 21.54 & - & - & - & 0.8 & - & - & - & - & - \\
\hline Copaene & 22.25 & - & 0.4 & - & - & - & - & - & - & - \\
\hline Azunol & 23.48 & - & - & - & 2.9 & - & - & - & - & - \\
\hline Oxygenated sesquiterpenes (\%) & & 5.2 & 2.2 & 1.1 & 48.9 & 3.9 & 0.7 & 0.4 & 0.8 & 7.1 \\
\hline Caryophyllene oxide & 20.98 & 3.6 & 0.9 & 0.2 & 8.0 & 0.8 & - & 0.4 & 0.8 & 3.7 \\
\hline Guaiol & 21.32 & 0.7 & - & - & 0.8 & 0.5 & - & - & - & - \\
\hline Unknown & 22.20 & - & - & - & 10.2 & - & - & - & - & - \\
\hline T-Cadinol & 22.55 & 0.9 & 0.7 & 0.4 & 17.8 & 1.6 & 0.7 & - & - & 3.4 \\
\hline$\alpha$-Cadinol & 22.94 & - & 0.6 & 0.5 & 11.5 & 1.0 & - & - & - & - \\
\hline$\beta$-Cadinol & 26.67 & - & - & - & 0.6 & - & - & - & - & - \\
\hline Diterpene hydrocarbons (\%) & & 1.4 & 2.6 & 0.0 & 0.0 & 0.0 & 0.0 & 0.0 & 0.0 & 0.0 \\
\hline Rimuen & 30.03 & 1.4 & 1.8 & - & - & - & - & - & - & - \\
\hline Labda-8(20),12,14,-triene & 30.39 & - & 0.4 & - & - & - & - & - & - & - \\
\hline Kaur-16-ene & 32.82 & - & 0.4 & - & - & - & - & - & - & - \\
\hline Oxygenated diterpenes (\%) & & 1.1 & 1.6 & 0.0 & 0.0 & 0.0 & 0.0 & 0.0 & 0.0 & 0.0 \\
\hline Verticiol & 31.79 & 1.1 & 1.6 & - & - & - & - & - & - & - \\
\hline Other $(\%)$ & & 79.2 & 89.3 & 86.4 & 6.0 & 5.8 & 8.6 & 97.8 & 96.6 & 72.9 \\
\hline Benzaldehyde & 4.12 & 1.7 & 2.2 & 0.8 & - & - & - & 3.8 & 3.4 & - \\
\hline Salicylaldehyde & 5.83 & - & - & - & - & 1.8 & 0.6 & - & - & 0.4 \\
\hline Benzyl alcohol & 8.32 & - & 0.4 & - & - & - & - & - & - & - \\
\hline 2-Methylbenzofuran & 8.65 & - & - & - & - & - & - & - & - & 14.4 \\
\hline Benzenepropanal & 8.71 & 4.5 & 3.6 & 1.1 & - & - & - & 6.3 & 5.4 & - \\
\hline$p$-Allylanisole & 9.60 & - & - & - & 3.8 & - & - & - & - & 0.8 \\
\hline Anethole & 9.64 & 1.8 & 1.1 & 0.6 & - & - & 0.9 & 1.6 & 1.6 & - \\
\hline cis-Cinnamaldehyde & 10.33 & 1.1 & 1.0 & 0.5 & - & - & - & 1.0 & 1.0 & - \\
\hline 4-Allyphenol & 11.29 & - & - & 0.3 & - & - & - & 0.4 & 0.6 & - \\
\hline trans-Cinnamaldehyde & 11.66 & 60.3 & 50.7 & 34.1 & 0.2 & 1.0 & 3.1 & 81.0 & 76.7 & 2.9 \\
\hline
\end{tabular}


Table 1 (continued)

\begin{tabular}{|c|c|c|c|c|c|c|c|c|c|c|}
\hline Compounds & $\mathrm{RT}^{\mathrm{a}}$ & $\mathrm{CO} 1$ & $\mathrm{CO} 2$ & $\mathrm{CO} 3$ & $\mathrm{CO} 4$ & $\mathrm{CO} 5$ & $\mathrm{CO} 6$ & $\mathrm{CO} 7$ & $\mathrm{CO} 8$ & $\mathrm{CO} 9$ \\
\hline Cinnamyl alcohol & 12.77 & - & - & 0.2 & - & - & - & - & - & - \\
\hline Eugenol & 14.29 & 2.4 & 1.6 & 4.5 & - & 2.3 & - & 2.8 & 2.5 & - \\
\hline Coumarin & 16.79 & - & - & - & 2.0 & - & 4.1 & - & - & - \\
\hline Cinnamyl acetate & 16.83 & 7.4 & 28.7 & 44.5 & - & 0.7 & - & 0.9 & 5.4 & 54.4 \\
\hline Identified components (\%) & & 99.5 & 99.0 & 100.0 & 86.6 & 99.9 & 99.8 & 100.0 & 100.0 & 92.6 \\
\hline Oil yield $(\%, v / d r y w t)$ & & 1.0 & 1.2 & 2.4 & 0.1 & 0.8 & 2.9 & 1.1 & 1.0 & 1.6 \\
\hline
\end{tabular}

${ }^{a}$ Retention time (min).

b Not detected.

pair-group method with arithmetic average (UPGMA) was used for cluster definition (Pereira et al., 2003).

\subsection{Statistical analysis}

The Scheffe multiple comparison procedure of SAS statistical program was used to analyze the difference of antifungal activities among nine $C$. osmophloeum leaf essential oils and their constituents $(p<0.05)$. All results were obtained from three independent experiments and expressed as mean $\pm \mathrm{SD}$.

\section{Results and discussion}

\subsection{Yields and chemical polymorphism of essential oils from different provenances}

The essential oil contents of nine provenances of $C$. osmophloeum leaves were obtained by hydrodistillation from a minimum of $0.1 \%$ dry weight to a maximum of $2.9 \%$ dry weight (Table 1). The highest oil yield was found in $\mathrm{CO} 6(2.9 \%)$, followed by $\mathrm{CO} 3(2.4 \%), \mathrm{CO} 9$ $(1.6 \%), \mathrm{CO} 2(1.2 \%), \mathrm{CO} 7(1.1 \%), \mathrm{CO} 8(1.0 \%), \mathrm{CO} 1$ $(0.9 \%), \mathrm{CO} 5(0.8 \%)$ and $\mathrm{CO} 4(0.1 \%)$.

Compositions of the nine essential oils are also reported in Table 1. A total of 56 compounds were identified in the nine leaf essential oils, representing $86.6-100.0 \%$ of the essential oils, respectively. The leaf essential oils of $\mathrm{CO} 1, \mathrm{CO} 7$ and $\mathrm{CO} 8$ were found to contain mainly cinnamaldehyde $(60.3 \%, 81.0 \%$ and $76.7 \%$, respectively). The main constituents of leaf essential oils from $\mathrm{CO} 2$ and $\mathrm{CO} 3$ were cinnamaldehyde $(50.7 \%$ and $34.1 \%)$ and cinnamyl acetate $(28.7 \%$ and $44.5 \%)$. The leaf essential oil of $\mathrm{CO} 9$ contains cinnamyl acetate as the major components $(54.4 \%)$ followed by 2 -methylbenzofuran $(14.4 \%)$. The leaf essential oil of $\mathrm{CO} 4$ was found to be rich in T-cadinol $(17.8 \%)$ and $\alpha$-cadinol $(11.5 \%)$. The major components of leaf essential oil of CO5 were camphor $(43.8 \%)$ and bornyl acetate $(20.6 \%)$. For leaf essential oil of CO6, its major constituent was linalool $(86.6 \%)$.

The major constituents identified in this study have also been reported in some previous studies related to the chemical analyses of Cinnamomum species. For instance, major compounds present in stem-bark oil and root-bark oil from cinnamon were $75 \%$ cinnamaldehyde and $56 \%$ camphor, respectively (Senanayake et al., 1978). Kaul et al. (2003) found that the major compound isolated from different parts of cinnamon oil was $(E)$-cinnamyl acetate $(22-65 \%)$. In another investigation, Jayaprakasha et al. $(1997,2000,2003)$ also reported the 34 compounds from cinnamon fruits and 26 compounds from cinnamon flowers with $(E)$-cinnamyl acetate $(42-54 \%)$ as their major compounds.

The differences in the percent composition of the essential oils among nine provenances of $C$. osmophloeum were determined by using cluster analysis (Fig. 1). Following the results obtained herein and the previous classification by $\mathrm{Hu}$ et al. (1985), we have classified the leaf essential oils into six main groups, cinnamaldehyde type (CO1, $\mathrm{CO} 7$ and $\mathrm{CO} 3)$, cinnamaldehyde/cinnamyl acetate type ( $\mathrm{CO} 2$ and $\mathrm{CO} 3)$, cinnamyl acetate type (CO9), camphor type (CO5) and linalool type (CO6), while the essential oil from $\mathrm{CO} 4$ was classified as a mixed type because of lack of a dominant compound.

\subsection{Antifungal activity of essential oils from different provenances}

Fig. 2 shows the antifungal activities of the leaf essential oils from six chemotypes of $C$. osmophloeum against

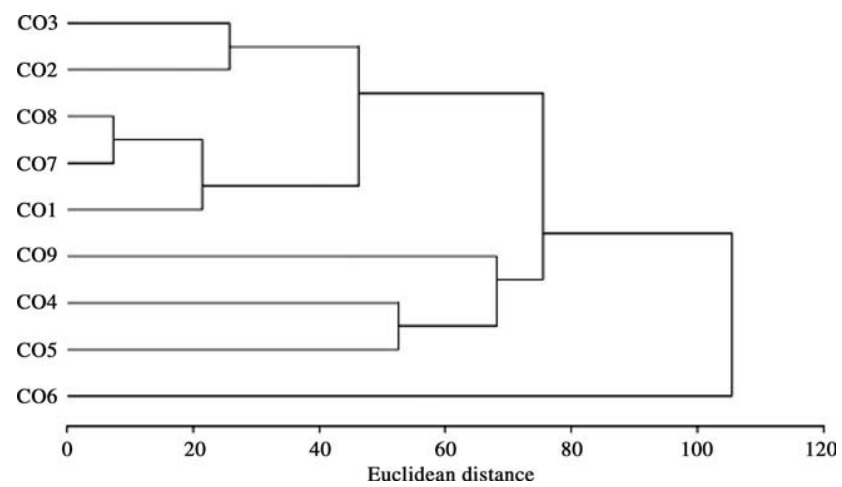

Fig. 1. Dendrogram obtained by cluster analysis of the percentage composition of essential oils from nine provenances of C. osmophloeum. 


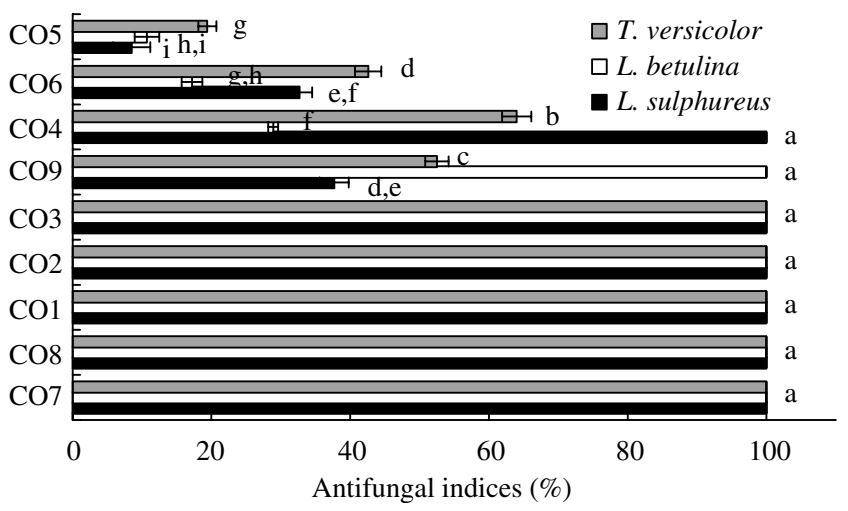

Fig. 2. Antifungal activities of leaf essential oils $(200 \mu \mathrm{g} / \mathrm{ml})$ from six chemotypes of $C$. osmophloeum against white-rot fungi $T$. versicolor and $L$. betulina and brown-rot fungus $L$. sulphureus. CO1, CO7, $\mathrm{CO} 8$ = cinnamaldehyde type $\mathrm{CO} 2, \mathrm{CO} 3$ = cinnamaldehyde/cinnamyl acetate type; $\mathrm{CO} 9=$ cinnamyl acetate type; $\mathrm{CO} 4=$ mixed type; CO6 $=$ linalool type; $\mathrm{CO} 5=$ camphor type. Each experiment was performed $\times 3$ and the data averaged $(N=3)$. Numbers followed by different letters $(\mathrm{a}-\mathrm{i})$ are significantly different at the level of $P<0.05$ according to the Scheffe test.

wood decay fungi at a concentration of $200 \mu \mathrm{g} / \mathrm{ml}$. Results showed that the leaf essential oils of cinnamaldehyde type (CO1, $\mathrm{CO} 7$ and $\mathrm{CO} 8)$ and cinnamaldehyde/ cinnamyl acetate type (CO2 and $\mathrm{CO} 3)$ completely inhibited the growth of brown-rot fungus ( $L$. sulphureus) and white-rot fungi ( $L$. betulina and $T$. versicolor) at the concentration of $200 \mu \mathrm{g} / \mathrm{ml}$. The $\mathrm{IC}_{50}$ values of both cinnamaldehyde type (CO1, $\mathrm{CO} 7$ and $\mathrm{CO} 8)$ and cinnamaldehyde/cinnamyl acetate type (CO2 and $\mathrm{CO} 3)$ leaf essential oils against $L$. sulphureus, $L$. betulina and $T$. versicolor were $52-112 \mu \mathrm{g} / \mathrm{ml}, 141-144 \mu \mathrm{g} / \mathrm{ml}$ and $131-$ $136 \mu \mathrm{g} / \mathrm{ml}$, respectively (Table 2 ). In addition, the antifungal indices of mixed type (CO4) against $L$. sulphureus and cinnamyl acetate type (CO9) against $L$. betulina were $100 \%$ (Fig. 2), and their $\mathrm{IC}_{50}$ values were 79 and $150 \mu \mathrm{g} / \mathrm{ml}$, respectively (Table 2 ). However, the antifungal indices of both camphor type (CO5) and linalool type (CO6) did not exceed 50\% (Fig. 2), and their $\mathrm{IC}_{50}$

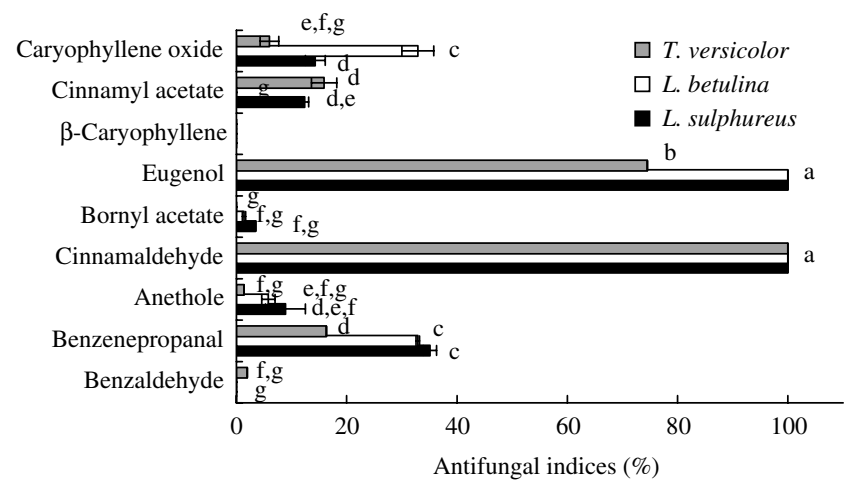

Fig. 3. Antifungal activities of the main constituents $(100 \mu \mathrm{g} / \mathrm{ml})$ of leaf essential oils from cinnamaldehyde type of $C$. osmophloeum against white-rot fungi $T$. versicolor and L. betulina and brown-rot fungus $L$. sulphureus. Each experiment was performed $\times 3$ and the data averaged $(N=3)$. Numbers followed by different letters $(\mathrm{a}-\mathrm{g})$ are significantly different at the level of $P<0.05$ according to the Scheffe test.

values were $>204 \mu \mathrm{g} / \mathrm{ml}$ (Table 2), indicating none of the leaf essential oils of these two chemotypes could inhibit the growth of brown-rot fungus (L. sulphureus) and white-rot fungi ( $L$. betulina and T. versicolor).

On the basis of the above results, it is found that the leaf essential oils of cinnamaldehyde type and cinnamaldehyde/cinnamyl acetate type have the strongest antifungal activities more than the other chemotypes. Since cinnamaldehyde type (CO1, CO7 and $\mathrm{CO} 8)$ and cinnamaldehyde/cinnamyl acetate type $(\mathrm{CO} 2)$ leaf essential oils contained a higher amount of cinnamaldehyde (Table 1) and also displayed strong antifungal activities, it is clear that the antifungal activities of these two leaf essential oils are directly affected by the cinnamaldehyde content. Singh and co-workers have proven that cinnamaldehyde is a strong antifungal agent against human pathogens (Singh et al., 1995). Furthermore, results from Table 2 also revealed that both chemotypes against brown-rot fungus displayed much stronger antifungal activity than against white-rot fungi. In addition, the

Table 2

$\mathrm{IC}_{50}$ values of leaf essential oils from six chemotypes of $C$. osmophloeum against white-rot fungi $T$. versicolor and $L$. betulina and brown-rot fungus L. sulphureus

\begin{tabular}{|c|c|c|c|}
\hline \multirow[t]{2}{*}{ Chemotypes } & \multirow{2}{*}{$\frac{\text { Brown-rot fungus }}{\text { L. sulphureus }}{ }^{\mathrm{a}}$} & \multicolumn{2}{|c|}{ White-rot fungi } \\
\hline & & L. betulina ${ }^{\mathrm{a}}$ & T. versicolor ${ }^{\mathrm{a}}$ \\
\hline Cinnamaldehyde type (CO7) & $52 \pm 3$ & $142 \pm 1$ & $135 \pm 2$ \\
\hline Cinnamaldehyde type (CO8) & $58 \pm 2$ & $141 \pm 1$ & $131 \pm 2$ \\
\hline Cinnamaldehyde type (CO1) & $59 \pm 2$ & $143 \pm 1$ & $133 \pm 2$ \\
\hline Cinnamaldehyde/cinnamyl acetate type (CO2) & $68 \pm 1$ & $141 \pm 1$ & $132 \pm 2$ \\
\hline Cinnamaldehyde/cinnamyl acetate type (CO3) & $112 \pm 3$ & $144 \pm 0$ & $136 \pm 2$ \\
\hline Cinnamyl acetate type (CO9) & $273 \pm 5$ & $150 \pm 0$ & $221 \pm 10$ \\
\hline Mixed type (CO4) & $79 \pm 5$ & $284 \pm 9$ & $148 \pm 10$ \\
\hline Linalool type (CO6) & $204 \pm 4$ & $301 \pm 10$ & $256 \pm 8$ \\
\hline Camphor type (CO5) & $412 \pm 4$ & $448 \pm 8$ & $>500$ \\
\hline
\end{tabular}

\footnotetext{
${ }^{\text {a }}$ Unit: $\mu \mathrm{g} / \mathrm{ml}$.
} 
Table 3

$\mathrm{IC}_{50}$ values of the main constituents of leaf essential oils from cinnamaldehyde type of $C$. osmophloeum against white-rot fungi $T$. versicolor and L. betulina and brown-rot fungus L. sulphureus

\begin{tabular}{|c|c|c|c|}
\hline \multirow[t]{2}{*}{ Compounds } & \multirow{2}{*}{$\frac{\text { Brown-rot fungus }}{\text { L. sulphureus }}$} & \multicolumn{2}{|c|}{ White-rot fungi } \\
\hline & & L. betulina $a^{\mathrm{a}}$ & T. versicolor ${ }^{\mathrm{a}}$ \\
\hline Benzaldehyde & $>500$ & $300 \pm 9$ & $495 \pm 10$ \\
\hline Benzenepropanal & $190 \pm 3$ & $203 \pm 4$ & $263 \pm 5$ \\
\hline Anethole & $>500$ & $>500$ & $>500$ \\
\hline Cinnamaldehyde & $73 \pm 2$ & $74 \pm 1$ & $73 \pm 2$ \\
\hline Bornyl acetate & $>500$ & $>500$ & $>500$ \\
\hline Eugenol & $71 \pm 2$ & $95 \pm 2$ & $92 \pm 1$ \\
\hline$\beta$-Caryophyllene & $>500$ & $>500$ & $>500$ \\
\hline Cinnamyl acetate & $458 \pm 10$ & $300 \pm 9$ & $328 \pm 8$ \\
\hline Caryophyllene oxide & $264 \pm 6$ & $147 \pm 5$ & $279 \pm 7$ \\
\hline DDAC $^{\mathrm{b}}$ & $1 \pm 0$ & $11 \pm 1$ & $11 \pm 0$ \\
\hline
\end{tabular}

a Unit: $\mu \mathrm{g} / \mathrm{ml}$.

b Didecyl dimethyl ammonium chloride.

mixed type leaf essential oil also exhibited significant effectiveness against $L$. sulphureus. It may be associated with the main constituents $(17.8 \%$ of $\mathrm{T}$-cadinol and $11.5 \%$ of $\alpha$-cadinol) of essential oil. In our previous studies on the antifungal performance of Taiwania cryptomerioides extractives and Calocedrus formosana leaf essential oil, it has been proven that $\alpha$-cadinol and $\mathrm{T}$ cadinol exhibited the highest antifungal activity against L. sulphureus (Chang et al., 1998, 2000; Cheng et al., 2004b).

\subsection{Antifungal activity of the constituents in essential oils}

The above-mentioned results showed that the cinnamaldehyde type and cinnamaldehyde/cinnamyl acetate type leaf essential oils had significant antifungal activities against wood decay fungi. To further understand the relative antifungal activity of the constituents in the leaf essential oils of cinnamaldehyde type and cinnamaldehyde/cinnamyl acetate type, we selected nine constituents in C. osmophloeum to analyze their antifungal performance. As shown in Fig. 3, cinnamaldehyde and eugenol exhibited the strongest activity against $L$. sulphureus, L. betulina and T. versicolor amongst the nine compounds tested. Both cinnamaldehyde and eugenol totally inhibited the growth of L. sulphureus and L. betulina at the concentration of $100 \mu \mathrm{g} / \mathrm{ml}$. Concerning $T$. versicolor, however, eugenol (antifungal index $=74.5 \%$ ) showed a lower activity than cinnamaldehyde (antifungal index $=100 \%$ ). The $\mathrm{IC}_{50}$ values of all these compounds in terms of antifungal activity against $L$. betulina and T. versicolor is ranked as cinnamaldehyde (74 and $73 \mu \mathrm{g} / \mathrm{ml})>$ eugenol $(95$ and $92 \mu \mathrm{g} / \mathrm{ml})>$ caryophyllene oxide (147 and $279 \mu \mathrm{g} / \mathrm{ml})>$ benzenepropanol (203 and $263 \mu \mathrm{g} / \mathrm{ml})>$ cinnamyl acetate $(300$ and $328 \mu \mathrm{g} / \mathrm{ml})>$ benzaldehyde ( 300 and $495 \mu \mathrm{g} / \mathrm{ml})>$ anethole $(>500 \mu \mathrm{g} /$ $\mathrm{ml})=$ bornyl acetate $(>500 \mu \mathrm{g} / \mathrm{ml})=\beta$-caryophyllene $(>500 \mu \mathrm{g} / \mathrm{ml})$ (Table 3$)$. On the other hand, the order of $\mathrm{IC}_{50}$ values against $L$. sulphureus is eugenol $(71 \mu \mathrm{g} /$ $\mathrm{ml})>$ cinnamaldehyde $\quad(73 \mu \mathrm{g} / \mathrm{ml})>$ benzenepropanol $(190 \mu \mathrm{g} / \mathrm{ml})>$ caryophyllene oxide $(264 \mu \mathrm{g} / \mathrm{ml})>$ cinnamyl acetate $(458 \mu \mathrm{g} / \mathrm{ml})>$ benzaldehyde $(>500 \mu \mathrm{g} /$ $\mathrm{ml})=$ anethole $(>500 \mu \mathrm{g} / \mathrm{ml})=$ bornyl acetate $(>500 \mu \mathrm{g} /$ $\mathrm{ml})=\beta$-caryophyllene $(>500 \mu \mathrm{g} / \mathrm{ml})($ Table 3$)$. Although cinnamaldehyde and eugenol all possess a stronger antifungal activity, eugenol exists in only minor quantities in the leaf essential oils of all $C$. osmophloeum provenances (CO1-CO9). Compared to DDAC, the standard fungicide which is known to be very effective against $L$. sulphureus, L. betulina and $T$. versicolor with $\mathrm{IC}_{50}$ values are 1,11 and $11 \mu \mathrm{g} / \mathrm{ml}$. It is interesting to note that all fungi were sensitive to cinnamaldehyde and the $\mathrm{IC}_{50}$ values are 73,74 and $73 \mu \mathrm{g} / \mathrm{ml}$. Therefore, cinnamaldehyde clearly is responsible for the excellent antifungal activity of cinnamaldehyde type (CO1, CO7 and CO8) leaf essential oils. A similar observation also was noted in our previous studies on the antitermite, antibacterial, antimite, antimildew, antimosquito and antipathogenic activities of C. osmophloeum (Chang et al., 2001; Chang and Cheng, 2002; Chen et al., 2002; Chen and Chang, 2002; Cheng et al., 2004a; Lee et al., 2005).

\section{Conclusions}

According to GC-MS and cluster analyses the leaf essential oils of the nine provenances and their relative contents were classified into six chemotypes - cinnamaldehyde type, cinnamaldehyde/cinnamyl acetate type, cinnamyl acetate type, linalool type, camphor type and mixed type. In addition, this study demonstrates that the cinnamaldehyde type and cinnamaldehyde/cinnamyl acetate type of $C$. osmophloeum leaf essential oils have excellent antifungal activities and that cinnamaldehyde is responsible for such activity. Therefore, cinnamaldehyde as well as the cinnamaldehyde type and cinnamaldehyde/cinnamyl acetate type leaf essential oils are renewable natural products and may be further explored 
as a potential source for the development of wood preservatives against decay fungi or fumigants in the near future.

\section{Acknowledgements}

This study was supported by a grant from the Council of Agriculture (COA) of the Executive Yuan, Taiwan. The authors thank COA for the financial support (92AS-2.3.3-FC-F1), Dr. Han-Ming Yu and Dr. ZennZong Chen of the Taiwan Forestry Research Institute and the Taiwan Da-Pin-Ting Sugar Farm for providing C. osmophloeum materials, and Dr. Sheng-Yang Wang and Pi-Wen Tsai of the Institute of BioAgricultural Sciences, Academia Sinica, Taiwan for assistance in the GC-MS analysis.

\section{References}

Chang, S.T., Cheng, S.S., 2002. Antitermitic activity of leaf essential oils and components from Cinnamomum osmophloeum. J. Agric. Food Chem. 50, 1389-1392.

Chang, S.T., Wu, C.L., Wang, S.Y., Su, Y.C., Kuo, Y.H., 1998. Studies on the antifungal compounds in the heartwood extractives of Taiwania (Taiwania cryptomerioides Hayata) (I): Isolation and identification of antifungal compounds in hexane soluble fraction. For. Prod. Ind. 17, 287-304.

Chang, S.T., Wang, S.Y, Wu, C.L., Su, Y.C., Kuo, Y.H., 1999. Antifungal compounds in the ethyl acetate soluble fraction of the extractives of Taiwania (Taiwania cryptomerioides Hayata) heartwood. Holzforschung 53, 487-490.

Chang, S.T., Wang, S.Y, Wu, C.L., Chen, P.F., Kuo, Y.H., 2000. Comparison of the antifungal activity of cadinane skeletal sesquiterpenoids from Taiwania (Taiwania cryptomerioides Hayata) heartwood. Holzforschung 54, 241-245.

Chang, S.T., Chen, P.F., Chang, S.C., 2001. Antibacterial activity of leaf essential oils and their constituents from Cinnamomum osmophloeum. J. Ethnopharmacol. 77, 123-127.

Chen, P.F., Chang, S.T., 2002. Application of essential oils from wood on the manufacture of environment-friendly antimicrobial paper products. Quart. J. Chin. For. 35, 69-74.

Chen, P.F., Chang, S.T., Wu, H.H., 2002. Antimite activity of essential oils and their components from Cinnamomum osmophloeum. Quart. J. Chin. For. 35, 397-404.

Cheng, S.S., Liu, J.Y., Tsai, K.H., Chen, W.J., Chang, S.T., 2004a. Chemical composition and mosquito larvicidal activity of essential oils from leaves of different Cinnamomum osmophloeum provenances. J. Agric. Food Chem. 52, 4395-4400.

Cheng, S.S., Wu, C.L., Chang, H.T., Kao, Y.T., Chang, S.T., $2004 b$. Antitermitic and antifungal activity of essential oil of Calocedrus formosana leaf and its composition. J. Chem. Ecol. 30, 1957-1967.

Hili, P., Evans, C.S., Veness, R.G., 1997. Antimicrobial action of essential oils: the effect of dimethylsulphoxide on the activity of cinnamon oil. Lett. Appl. Microbiol. 24, 269-275.

Hu, T.W., Lin, Y.T., Ho, C.K., 1985. Natural variation of chemical components of the leaf oil of Cinnamomum osmophloeum Kaneh. Bull. Taiwan For. Res. Inst. Eng. 78, 296-313.

Jayaprakasha, G.K., Jagan Mohan Rao, L., Sakariah, K.K., 1997. Chemical composition of the volatile oil from the fruits of Cinnamomum zeylanicum Blume. Flavour Fragr. J. 12, 331-333.

Jayaprakasha, G.K., Jagan Mohan Rao, L., Sakariah, K.K., 2000. Chemical composition of the flower oil of Cinnamomum zeylanicum Blume. J. Agric. Food Chem. 48, 4294 4295.

Jayaprakasha, G.K., Jagan Mohan Rao, L., Sakariah, K.K., 2003. Volatile constituents from Cinnamomum zeylanicum fruit stalks and their antioxidant activities. J. Agric. Food Chem. 51, 43444348.

Kaul, P.N., Bhattacharya, A.K., Rajeswara Rao, B.R., Syamasundar, K.V., Ramesh, S., 2003. Volatile constituents of essential oils isolated from different parts of cinnamon (Cinnamomum zeylanicum Blume). J. Sci. Food Agric. 83, 53-55.

Kim, H.O., Park, S.W., Park, H.D., 2004. Inactivation of Escherichia coli $\mathrm{O} 157: \mathrm{H} 7$ by cinnamic aldehyde purified from Cinnamomum cassia shoot. Food Microbiol. 21, 105-110.

Lee, H.C., Cheng, S.S., Chang, S.T., 2005. Antifungal property of the essential oils and their constituents from Cinnamon osmophloeum leaf against tree pathogenic fungi. J. Sci. Food Agric. 85, in press.

Liu, Y.C., Lu, F.Y., Ou, C.H., 1998. Trees of Taiwan; Monographic Public No. 7. College of Agriculture, National Chung-Hshing University, Taichung, Taiwan, p. 136.

Ouattara, B., Simard, R.E., Holley, R.A., Piette, G.J.P., Begin, A., 1997. Antibacterial activity of selected fatty acids and essential oils against six meat spoilage organisms. Int. J. Food Microbiol. 37, $155-162$.

Park, I.K., Lee, H.S., Lee, S.G., Park, J.D., Ahn, Y.J., 2000. Insecticidal and fumigant activities of Cinnamomum cassia barkderived materials against Mechoris ursulus (Coleoptera: Attelabidae). J. Agric. Food Chem. 48, 2528-2531.

Pereira, S.I., Santos, P.A.G., Barroso, J.G., Figueiredo, A.C., Pedro, L.G., Salgueiro, L.R., Deans, S.G., Scheffer, J.J.C., 2003. Chemical polymorphism of the essential oils from populations of Thymus caespititius grown on the islands Pico, Faial and Graciosa (Azores). Phytochem. Anal. 14, 228-231.

Senanayake, U.M., Lee, T.H., Wills, R.B.H., 1978. Volatile constituents of cinnamon (Cinnamomum zeylanicum) oils. J. Agric. Food Chem. 26, 822-826.

Singh, H.B., Srivastava, M., Singh, A.B., Srivastava, A.K., 1995. Cinnamon bark oil, a potent fungitoxicant against fungi causing respiratory tract mycoses. Allergy 50, 995-999. 